\title{
EUS-FNA and EBUS-TBNA; the pulmonologist's and surgeon's perspective
}

M. Krasnik ${ }^{3}$, P. Vilmann², F. Herth

${ }^{1}$ Department of Surgical Gastroenterology, Gentofte University Hospital, Copenhagen, Denmark

2 Department of pulmonary medicine, thorax clinic Heidelberg, Heidelberg, Germany

${ }^{3}$ Department of cardiothoracic surgery, Gentofte University Hospital, Copenhagen, Denmark²

Introduction

Lung cancer is the leading cancer related cause of death in the western world [1]. The prognosis is directly related to the stage of the disease. Treatment strategies are largely based on the cell type of the tumor, i.e. either small cell lung cancer (SCLC) or nonsmall cell lung cancer (NSCLC), and the presence of mediastinal involvement or distant spread of the tumor $[1,2]$. The treatment of SCLC is mainly chemotherapy whereas NSCLC treatment is fully stage dependent ranging from surgery only to down-staging chemotherapy with subsequent surgery or entirely experimental chemotherapy/radiotherapy.

Non-small cell lung cancer (NSCLC) usually metastasizes first to hilar and mediastinal lymph nodes. Subsequently, hematogenous metastasis to distant sites may occur. Because survival is inversely correlated with stage, a meticulous staging procedure is required to determine the treatment and prognosis $[3,4]$. For staging of NSCLC, the TNM classification has been developed, in which $\mathrm{T}$ stands for local tumor extension, $\mathrm{N}$ for lymph node metastasis, and $\mathrm{M}$ for distant metastasis. The lymph node map by Mountain et al, and its revisions are often used for the description of the $\mathrm{N}$ factor of the TNM classification [5] (Table $\mathbf{1}$ and $\mathbf{2}$ ).

\section{TNM Classification}

The TNM classification is subdivided in CTNM and a pTNM where the cTNM is based on the clinical evaluation while the PTNM is based on the pathological results after operation.

The difference in the 5 years survival based on the cTNM classification compared to the pTNM stresses the importance of an exact classification (Fig. 1 and $\mathbf{2}$ ).

Exact mediastinal staging of patients with non-small-cell lung cancer (NSCLC) is therefore important to improve selection of the treatment of patients with lung cancer. Up to $10 \%$ of lung cancer operations result in explorative thoracotomies without

Correspondence: Mark Krasnik - Department of Thoracic and Cardiovascular Surgery · Gentofte University Hospital · Niels Andersensvej 65 - 2900 Hellerup . Denmark·Fax: 397776 44·Phone: +45 397738 10·E-mail: mkrasniki@thoraxt.dk

Bibliography: Endoscopy 2006; 38 (S1): S105-S109 @ Georg Thieme Verlag KG Stuttgart · New York · ISSN 0013-726X · DOI 10.1055/s-2006-946659 
Primary tumor

- Tis - Carcinoma in situ

- TX - Positive malignant cytologic findings, no lesion observed

- T1 - diameter of $3 \mathrm{~cm}$ or smaller and surrounded by lung or visceral pleura (see Image 1) or endobronchial tumor distal to the lobar bronchus

. T2 - Diameter greater than $3 \mathrm{~cm}$ (see Images 2 - 3); extension to the visceral pleura, atelectasis, or obstructive pneumopathy involving less than 1 lung; lobar endobronchial tumor; or tumor of a main bronchus more than $2 \mathrm{~cm}$ from the carina

- T3 - Tumor at the apex (see Image 5); total atelectasis of 1 lung; endobronchial tumor of main bronchus within $2 \mathrm{~cm}$ of the carina but not invading it; or tumor of any size with direct extension to the adjacent structures such as the chest wall mediastinal pleura (see Image 8), diaphragm, pericardium parietal layer, or mediastinal fat of the phrenic nerve

. T4 - Invasion of the mediastinal organs, including the esophagus trachea, carina (see Image 11), great vessels (see Image 13), and/or heart; obstruction of the superior vena cava; involvement of a vertebral body; recurrent nerve involvement; malignant pleural or pericardial effusion; or satellite pulmonary nodules within the same lobe as the primary tumor

- Regional lymph node involvement

- NO - No lymph nodes involved

- N1 - Ipslateral bronchopulmonary or hilar nodes involved

- N2 - Ipsilateral mediastinal nodes or ligament involved

- Upper paratracheal lower paratracheal nodes

- Pretracheal (see Image 4, Image 7, Image 10) and retrotracheal nodes

- Aortic and aortic window nodes

- Para-aortic nodes

- Para-esophageal nodes

- Pulmonary ligament

- Subcarinal nodes (see Images 12-17)

- N3 - contralateral mediastinal or hilar nodes involved (see image 19) or any scalene or supraclavicular nodes involved

- Metastatic involvement

- M0 - No metastases

- M1 - Metastases present (see Images 20-27)

Table 2 Stage groupings

- IA - T1NOMO

- IB - T2NOMO

- $\mathrm{IIA}-\mathrm{T} 1 \mathrm{~N} 1 \mathrm{M} 0$

- $I I B-T 2 N 1 M 0$ or T3NOMO

- IIIA - T1-3N2M0 or T3N1M0

- IIIB - Any T4 or any N3M0

- IV - Any M1

tumor resection, and an additional $25-35 \%$ of the operations are unsuccessful because of postoperative recurrent disease $[6,7]$, apparently because the stage of the disease is more advanced than expected preoperatively.

Therefore the correct staging is critical because treatment is directly related to the stage of the. Thus, incorrect staging would lead to improper treatment, and material demunition of patient survivability (Fig. 3).

Mediastinal lymph node staging can be divided into imaging and sampling. Computed tomography (CT), magnetic resonance imaging (MRI), and positron emission tomography (PET) may be used to image mediastinal lymph nodes [8]. Pathologic sampling of suspicious lesions can be performed by mediastinoscopy, thoracoscopy, transthoracic fine-needle aspiration, transbronchial fine-needle aspiration, and endoscopic ultrasonography with fine-needle aspiration [8-11].

\section{CT}

The background of the differences in 5 years survival in CTNM and pTNM is based on the sensitivity and diagnostic values of the different modalities used in the cTNM classification compared to the operative findings.

Neither CT scan nor MRI are able to distinguish malignant from hyper plastic, anthracotic, granulomatous or fibrotic lesions, more so after induction treatment. With reported sensitivities and specificities of $69 \%$, respective $71 \%$ for CT scan and $45 \%$, respective $65 \%$ for MRI, both techniques prove too inaccurate for reliable loco regional staging.

Looking at the different objects in the TNM staging system, the accuracy in T staging is $60 \%$ and $\mathrm{N}$ staging $65 \%$.

This result is depended of the $\mathrm{N}$ stage because the accuracy here is $65 \%$ for N0, $42 \%$ for N1, 32\% for N2 and $43 \%$ for N3. Therefore $\mathrm{N}$ under staging is found in $23 \%$ and an over staging in $30 \%$.

By CT scan which is one of the main methods in evaluating lung cancer the N-classification is only correct in $50 \%$, over staged in $25 \%$ and under staged in $25 \%[13,14]$.

\section{FDG PET}

Many retrospective $[15,16]$ and prospective studies [17 - 19] have shown FDG PET to be an accurate imaging modality in the nodal 

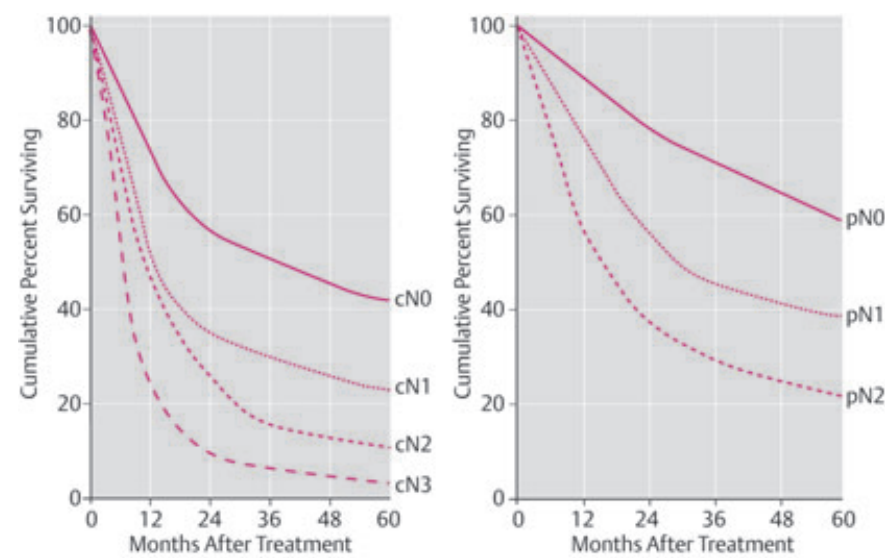

Fig. 15 year survival $\mathrm{cN}$ versus $\mathrm{pN}$.
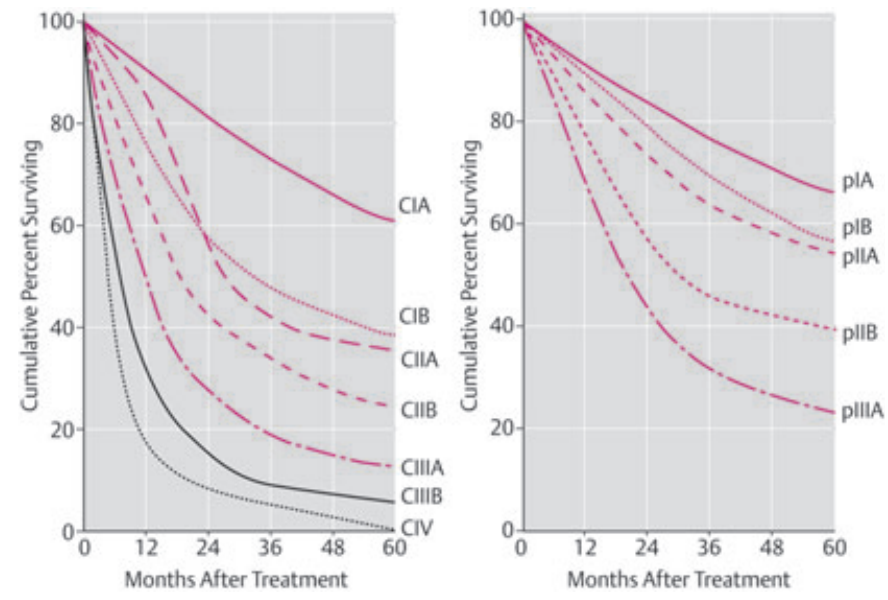

Fig. 2 Survival cTNM versus PTMN.

\begin{tabular}{|c|c|c|c|}
\hline \multicolumn{2}{|c|}{ Operable } & \multicolumn{2}{|c|}{ Inoperable } \\
\hline$\square$ St. la & T1NOMO & $\square$ St. Illa & T1N2M0 \\
\hline$\square$ St. Ib & T2NOMO & & T3N1N2M0 \\
\hline$\square$ St. Ila & T1N1M0 & $\square$ St. IIIb & $\begin{array}{l}\text { Any TN3M0 } \\
\text { T4 any NM0 }\end{array}$ \\
\hline$\square$ St. IIb & $\begin{array}{l}\text { T2N1M0 } \\
\text { T3NOM0 }\end{array}$ & $\square$ St. VI & Any T any NM1 \\
\hline
\end{tabular}

Fig. 3 Operability by stage.

staging of NSCLC. Meta-analytic comparisons of PET and CT [2023] showed that PET was significantly more accurate than $\mathrm{CT}$ in demonstrating nodal metastases.

However, a metaanalysis (eller er det et review) has shown that PET/CT has a sensitivity of 0.84 , a specificity of 0.89 and a PPV of 0.79 and a NPV of 0.93 [24].

The diagnostic capability of FDG PET is limited not only by cellular activity but also by tumor volume. FDG uptake by small tumor cell foci is often poorly depicted due to partial volume effect. Current PET scanner achieves transaxial resolution of 4-5 mm full-width-half-maximum. A tumor focus smaller than $5 \mathrm{~mm}$ may not be detected by the current scanners. The maximum dimensions of tumor focus in false-negative lymph nodes ranges from 1 to $7.5 \mathrm{~mm}$ (mean $3.4 \mathrm{~mm}$ ) [25].

Yoshida et al. [25] showed that the spatial resolution limitations of FDG PET were responsible for 13 of 14 (93\%) false-negative PET results demonstrating that FDG PET is not reliable in diagnosing small tumor foci in Lymph nodes.

Another disadvantage of FDG PET is its limited anatomical resolution due to the paucity of anatomic information in metabolic images [19]. Although PET-positive Lymph nodes were localized referring to contrast-enhanced CT findings, it is hard to distinguish hillar Lymph nodes from adjacent mediastinal Lymph nodes.

False-positive PET scans is mostly attributable to inflammatory conditions, including tumor necrosis, obstructive pneumonia, previous pulmonary tuberculosis, pulmonary fibrosis, and rheumatoid arthritis. FDG is not a specific marker of malignancy and FDG uptake can be seen at sites of active, acute inflammation, which is due to increased glucose uptake by activated macrophages and inflammatory cells [26]. Inflammatory conditions are well-known factors associated with false-positive PET scans in indeterminate pulmonary nodule evaluation [27]. Roberts et al. [28] reported that concurrent inflammatory lung disease and centrally located tumors were causative factors of false-positive PET scans in mediastinal nodal staging in NSCLC.

Fritscher-Ravens et al. showed that in using EUS FNA, PET and CT they found false positive inoperable diagnoses: $\mathrm{PET}=9 / 36$, $\mathrm{CT}=3 / 20$.

Sensitivity, specificity, accuracy in nodal staging for CT was 29 , 83 , and $65 \%$ and for PET 39,79 , and $66 \%$, respectively. There were $10(14 \%)$ false-positive PET scans and 14 (20\%) false-negative PET scans.

\section{Mediastinoscopy}

Preoperative evaluation of the mediastinal lymph nodes is important in patients with lung cancer in order to determine operability and/or need for neoadjuvant treatment. 46 years after its introduction by Carlen's in 1959 [31], mediastinoscopy is still the golden standard in the evaluation of the mediastinal lymph node and in the preoperative staging of patients with lung cancer $[32,33]$. Mediastinal exploration is described as cervical mediastinoscopy, parasternal mediastinotomy, extended cervical mediastinoscopy and thoracoscopy depending on the surgical technique. Cervical mediastinoscopy (CM) is generally accepted as a safe and highly accurate procedure in the staging of lung cancer. Nodes accessible to CM are those of the superior (level $2 R$ and $2 \mathrm{~L}$ ) and inferior (level 4R and 4L) Para tracheal and subcarinal (level 7) nodal stations. Additionally, extended CM and left parasternal mediastinotomy allow exploration of the aortopulmonary window (level 5) and anterior mediastinal nodes (level 6) (Fig. 4). 


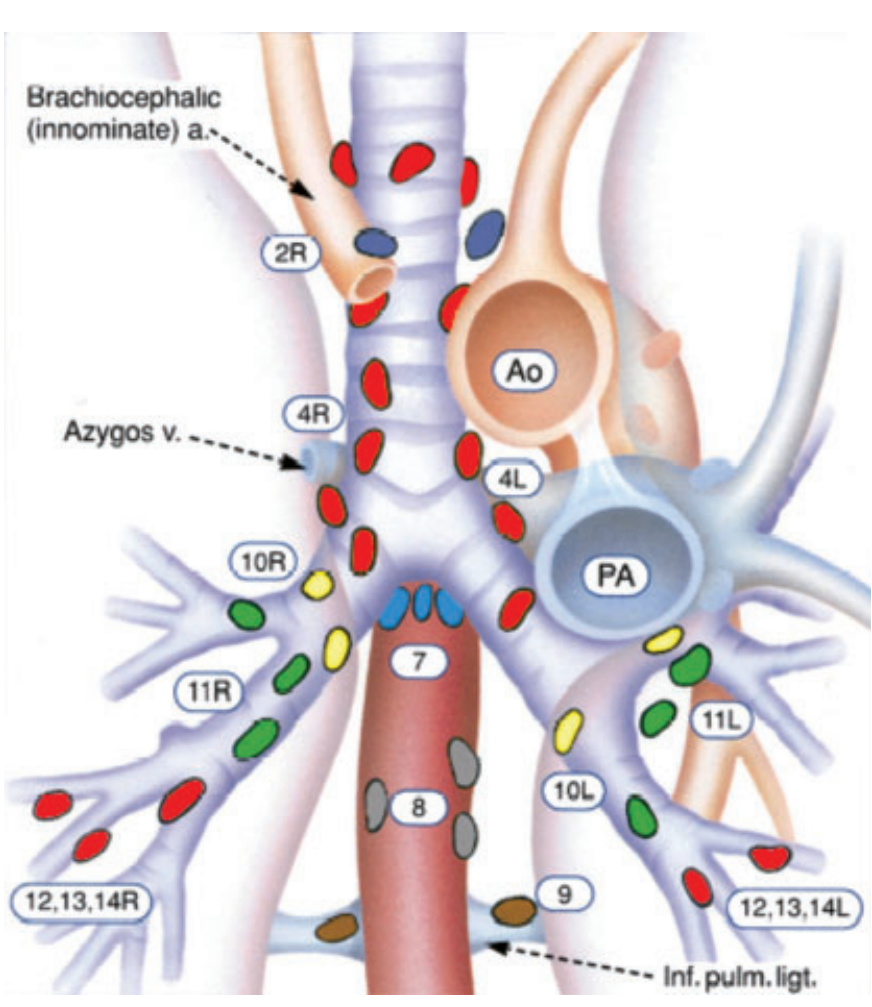

Fig. 4 Mediastinal and hillar lymph nodes stations.

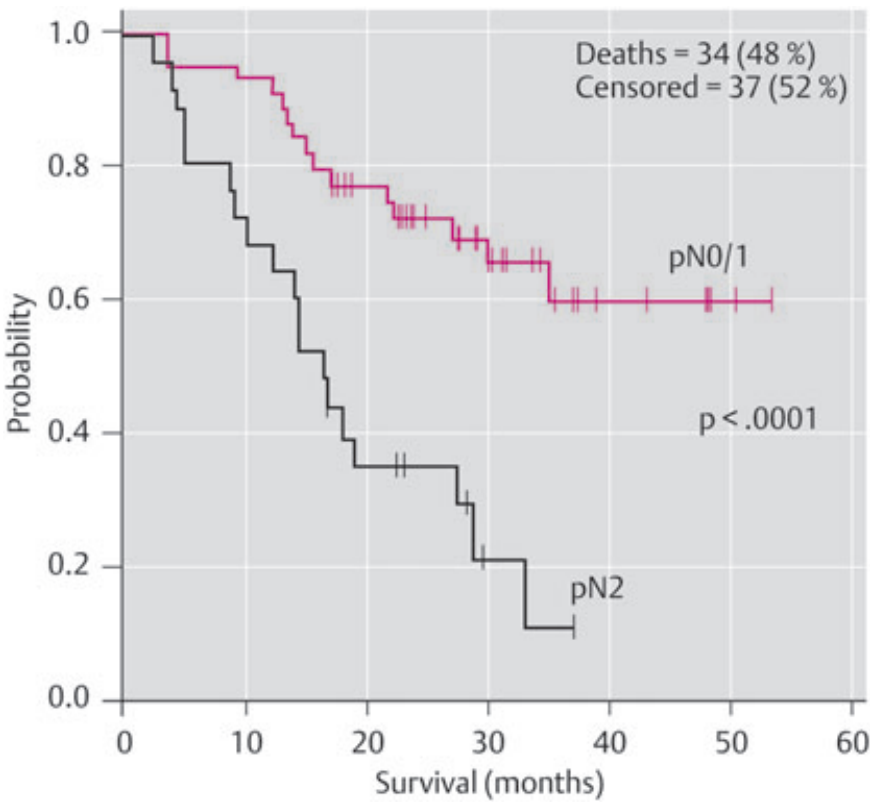

Fig. 5 Overall survival dependent on pN2 clearance in the univariate analysis (patients with tumor resection after downstaging treatment), $\mathrm{n}=71 ; \mathrm{P}=$ log-rank test $\mathrm{P}$ value Sugerbaker: ASCO Educational book, 1994.

A special problem is remediastinoscopy (RM) because of fibrosis due to the first procedure and the associated risk of injury to vital structures [34-36]. Neoadjuvant clinical trials with induction chemotherapy or chemo radiation should all involve a restaging procedure to confirm the differences in the results of different treatment modalities. In downstaged patients restaging is also important to select therapy-responsive patients with high probability of complete resectability, thereby reducing the number of futile thoracotomies in patients with locally advanced lung cancer [37-39].

\section{EUS-FNA and EBUS-TBNA}

To establish an easier and more accurate staging procedure EBUS TBNA and EUS FNA has been developed. They target lesions and lymph nodes adjacent to trachea, main bronchi and esophagus and the hillar regions. Both techniques are used to assess the entire mediastinum or to stage predominantly only one nodal station, and can be used for the systematical standardized exploration of individual nodes as performed by mediastinoscopy [41 45].

\section{Comments}

With the current status and the development of the multidisciplinary treatment modalities it is outmost important that we solve the basic problems with the imaging systems which do not enable us to establish an exact diagnosis and a precise stage because we need cells for an exact diagnose.

Mediastinoscopy is still the golden standard but has its limitations, i. e. incomplete mediastinoscopy, most frequently seen at station 7 and the posterior and inferior mediastinum, assessment of loco regional extent of recurrent cancer, a second primary cancer, re-staging after neoadjuvant chemotherapy and metastases from cancers in other organs to the mediastinum and hillar regions.

Remediastinoscopies is although possible often difficult to perform but it is very important to establish a correct stage also after downstaging so only patients who benefits from operation will be offered this treatment (Fig. 5).

The often undiagnosed hillar lymph nodes metastases in N1 nodes, is a special problem. Traditionally hey can only be reached by thoracotomy (scopy). Because of the possibilities of neoadjuvant therapy in primary lung cancer it is nessecary also to diagnose the $\mathrm{N} 1$ lymphnodes. In the evaluation of patients after downstaging a correct restaging is important in evaluating the results from different treatment modalities, Metastasis from other organs is also often found in the N1 nodes.

In the staging process of $\mathrm{cN} 1$ disease, it is possible to perform mediastinoscopy and thoracoscopy to avoid unnecessary thoracotomy especially in adenocarcinoma, even though mediastinal nodes and pleural dissemination were negative on computed tomography investigation. These methods requires general anesthesia and open surgery.

Therefore we need a method which is easy and minimal invasive, based on an outpatient procedure and enables us to collect tissue on which basis a diagnose can be established and the stage of cancers can be determined so a proper and effective treatment can be established. 
${ }^{1}$ American College of Chest Physicians; Health and Science Policy Committee. Diagnosis and management of lung cancer: ACCP evidencebased guidelines. American College of Chest Physicians. Chest 2003; 123 (1 Suppl): DG, 1S-337S

2 Silvestri GA, Tanoue LT, Margolis ML, Barker J, Detterbeck F; American College of Chest Physicians. The noninvasive staging of nonsmall cell lung cancer: the guidelines. Chest. 2003; 123 (1 Suppl): $147 \mathrm{~S}-156 \mathrm{~S}$

3 Sihoe AD, Yim AP. Lung cancer staging. J Surg Res 2004; 117: 92 - 106

${ }^{4}$ Spira A, Ettinger DS. Multidisciplinary management of lung cancer. N Engl J Med. 2004; 350: 379 - 392

${ }^{5}$ Mountain CF, Dresler CM. Regional lymph node classification for lung cancer staging. Chest 1997; 111: 1718-1723

${ }^{6}$ Herder GJ, Verboom P, Smit EF, van Velthoven PC, van den Bergh JH, Colder CD. Practice, efficacy and cost of staging suspected non-small cell lung cancer: a retrospective study in two Dutch hospitals. Thorax 2002; 57: $11-14$

${ }^{7}$ Canadian Lung Oncology Group. Investigation for mediastinal disease in patients with apparently operable lung cancer. Ann Thorac Surg 1995; 60: 1382 - 1289

8 Toloza EM, Harpole L, Detterbeck F, McCrory DC. Invasive staging of non-small cell lung cancer: a review of the current evidence. Chest 2003; $123: 157-66$

${ }^{9}$ Garpestad E, Goldberg S, Herth F et al. CT fluoroscopy guidance for transbronchial needle aspiration: an experience in 35 patients. Chest 2001; 119: $329-332$

10 Mehta AC, Kavuru MS, Meeker DP, Gephardt GN, Nunez C. Transbronchial needle aspiration for histology specimens. Chest 1989; 96: $1268-1272$

11 Vilmann P, Hancke S. A new biopsy handle instrument for endoscopic ultrasound guided biopsy. Gastrointest Endosc 1996; 43: 238 - 242

12 Klaus L. Prenzel, Stefan P. Mönig, Jan M. Sinning, Stephan E. Baldus, Hans-Georg Brochhagen, Paul M. Schneider, and Arnulf H. Hölscher Lymph Node Size and Metastatic Infiltration in Non-small Cell Lung Cancer. Chest Feb 2003; 123: 463 -467

13 Mornex P, Loubeyre P, Giraud O, Chapet P, van Houtte P, Bonnette, Sentenac I. Volume tumoral macroscopique et volume-cible anatomoclinique en radiothérapie : cancer bronchique: GTV and CTV in radiation therapy: lung cancer Cancer/Radiothérapie; Volume 5, Issue 5 October 2001: 659-670

14 Naruke T, Suemasu K, Ishikawa S. Lymph node mapping and curability at various levels of metastasis in resected lung cancer. 1978; 76: 832 839

15 Gupta NC, Tamim WJ, Graeber GG, Bishop HA, Hobbs GR. Mediastinal lymph node sampling following positron emission tomography with fluorodeoxyglucose imaging in lung cancer staging. Chest 2001; 120 : $521-527$

${ }^{16}$ Marom EM, McAdams HP, Erasmus JJ, Goodman PC, Culhane DK, COleman RE. Staging non-small cell lung cancer with whole-body PET. Radiology. 1999; 212 (3): 803 - 809

17 Pieterman RM, van Putten JW, Meuzelaar JJ, Mooyaart EL, Vaalburg W, Koeter GH. Preoperative staging of non-small-cell lung cancer with positron-emission tomography. N Engl J Med 2000; 343: 254 - 261

18 Vansteenkiste JF, Stroobants SG, De Leyn RP, Dupont PJ, Bogaert J, Maes A. Node staging in non-small-cell lung cancer with FDG-PET scan: a prospective study on 690 lymph node stations from 68 patients. J Clin Oncol 1998; 16: 2142-2149

19 Valk PE, Pounds TR, Hopkins DM, Haseman MK, Hofer GA, Greiss HB. Staging non-small cell lung cancer by whole-body positron emission tomographic imaging. Thorac Surg 1995; 60: 1573-1581

${ }^{20}$ Damena SS, Sonnad JO, Angobaldo, Wahl RL. Metastases from nonsmall cell cancer: mediastinal staging in the 1990s-meta-analytic comparison of PET and CT. Radiology 1999; 213: 530-536

21 Toloza EM, Harpole L, McCrory DC. Non-invasive staging of non-small cell lung cancer: lung a review of the current evidence. Chest 2003; 123: $137 \mathrm{~S}-146 \mathrm{~S}$

22 Gould MK, Kuschner WG, Rydzak CE, Maclean CC, Demas AN, Shigemitsu $\mathrm{H}$. Test performance of positron emission tomography and computed tomography for mediastinal staging in patients with non-smallcell lung cancer: a meta-analysis. Ann Intern Med 2003; 139: 879 892
${ }^{23}$ Hellwig D, Ukena D, Paulsen F, Bamberg M, Kirsch CM. Meta-analysis of the efficacy of positron emission tomography with F-18-fluorodeoxyglucose in lung tumors Basis for discussion of the German Consensus Conference on PET in Oncology. Pneumologie 2001; 55: 367 - 377

${ }^{24}$ Marom EM, McAdams HP, Erasmus JJ, Goodman PC, Culhane Dk, Coleman RE, Herndon JE. Staging non-small cell lung cancer with wholebody PET. Radiology 1999 Sep; 212 (3): 803 - 809

25 Kazuya Takamochi Junji Yoshida, Koji Murakami, Seiji Niho, Genichiro Ishii, Mitsuyo Nishimura, Yutaka Nishiwaki, Kazuya Suzuki, Kanji Nagai. Pitfalls in lymph node staging with positron emission tomography in non-small cell lung cancer patients. Lung Cancer2005; 47: 235 242

${ }^{26}$ Kubota R, Kubota K, Yamada S, Tada M, Ido T, Tamahashi N. Microautoradiographic study for the differentiation of intratumoral macrophages, granulation tissues and cancer cells by the dynamics of fluorine-18-fluorodeoxyglucose uptake. J Nucl Med 1994; 35: 104 - 112

27 Dewan NA, Gupta NC, Redepenning LS, Phalen JJ, Frick MP. Diagnostic efficacy of PET-FDG imaging in solitary pulmonary nodules. Potential role in evaluation and management. Chest 1993; 104: 997-1002

28 Roberts PF, Follette DM, von Haag D, Park JA, Valk PE, Pounds TR et al. Factors associated with false-positive staging of lung cancer by positron emission tomography. Ann Thorac Surg 2000; 70: 1154-1159

${ }^{29}$ Fritscher-Ravens A et al. EUS, PET and CT for lung cancer. Am J Respir Crit Care Med 2003; 168: 1293 - 1297

30 Shun-ichi Watanabe MD, Hisao Asamura MD, Kenji Suzuki MD and Ryosuke Tsuchiya MD. The Annals of Thoracic Surgery. 2005; 79 (5): $1682-1685$

${ }^{31}$ Carlens EL. Mediastinoscopy: method for inspection and tissue biopsy in the superior mediastinum. Dis Chest 1959; 36: $343-352$

32 Gossot D, Toledo L, Fritsch S et al. Mediastinoscopy versus thoracoscopy for mediastinal biopsy: results of a prospective nonrandomized study. Chest 1996; 110: 1328 - 1931

33 Rendina EA, Venuta F, de Giacomo T et al. Comparative merits of thoracoscopy, mediastinoscopy and mediastinotomy for mediastinal biopsy. Ann Thorac Surg 1994; 57: 992 - 995

34 Palva T, Palva A, Karja J. Re-mediastinoscopy. Arch Otolaryngol 1975; 101: $748-750$

35 Lewis RJ, Sisler GE, Mackenzie JW. Repeat mediastinoscopy. Ann Thorac Surg 1984; 37: 147 - 149

${ }^{36}$ Balle VH, Bretlau P. Remediastinoscopy. J Layngol Otol 1985; 99: 267 271

37 Mateu-Navarro M, Rami-Porta R et al. Remediastinoscopy after induction chemotherapy in non-small cell lung cancer. Ann Thorac Surg 2000; 70: 391 - 395

38 Schil Pvan, Schoot Jvander, Poniewierski J et al. Remediastinoscopy after neoadjuvant therapy for non-small cell lung cancer. Lung Cancer 2002; 37: $281-285$

39 Stamatis G, Greschuchna D. Role of cervical remediastinoscopy in the restaging of bronchogenic carcinoma. Abstract STS. 31st. Annual Meeting, Palm Springs: 1995

${ }^{40}$ Meersschaut D, Vermassen F, de la Rivière AB et al. Repeat mediastinoscopy in the assessment of new and recurrent lung neoplasm. Ann Thorac Surg 1992; 53: 120-122

${ }^{41}$ Larsen SS, Krasnik M, Vilmann P, Jacobsen GK, Pedersen JH, Faurschou $\mathrm{P}$, Folke K. Endoscopic ultrasound guided biopsy of mediastinal lesions has a major impact on patient management. Thorax 2002; 57 (2): 98 103

42 Krasnik M. Endoscopic transesophageal and endoscopic transbronchial real-time ultrasound-guided biopsy. Respiration 2003; 70 (3): $293-298$

43 Larsen SS, Vilmann P, Krasnik M, Dirksen A, Clementsen P, Skov BG, Jacobsen GK. Endoscopic ultrasound guided biopsy versus mediastinoscopy for analysis of paratracheal and subcarinal lymph nodes in lung cancer staging. Lung Cancer 2005; 48 (1): 85 -92

${ }^{44}$ Larsen SS, Vilmann P, Krasnik M, Dirksen A Clementsen P, Maltbaek N, Lassen U, Skov BG, Jacobsen GK. Endoscopic ultrasound guided biopsy performed routinely in lung cancer staging spares futile thoracotomies: preliminary results from a randomised clinical trial. Lung Cancer 2005; 49 (3): 3

45 Vilmann P, Krasnik M, Larsen SS, Jacobsen GK, Clementsen P. Transesophageal endoscopic ultrasound-guided fine-neddle asoiration (EUS-FNA) and endobronchial ultrasound-guided transbronchial needle aspiration (EBUS-TBNA) biopsy: a combined approach in the evaluation of mediastinal lesions. Endoscopy 2005; 37 (9): $833-839$ 